Sharif University of Technology
Scientia Iranica
Transactions E: Industrial Engineering
hCIENTIA

\title{
Multi-period configuration of forward and reverse integrated supply chain networks through transport mode
}

\author{
A. Eydi ${ }^{a, *}$, S. Fazayeli ${ }^{\mathrm{b}}$, and H. Ghafouri ${ }^{\mathrm{b}}$ \\ a. Faculty of Engineering, University of Kurdistan, Sanandaj, Iran. \\ b. Department of Industrial Engineering, University of Kurdistan, Sanandaj, Iran.
}

Received 25 September 2017; received in revised form 25 August 2018; accepted 15 October 2018

\author{
KEYWORDS \\ Supply chain network \\ design; \\ Forward and reverse \\ logistic; \\ Multi-period \\ programming; \\ Transportation mode; \\ Genetic algorithm.
}

\begin{abstract}
In today's competitive business, buying and returning products have become a common practice because of incompleteness of the products or the failure to meet the customer's satisfaction or reusing products. Before handling this cycle, companies need a proper logistics network because of its impact on the efficiency and responsiveness of the supply chain. In this research, a forward and reverse logistics network was proposed for product distribution and collection. The contribution of this paper is a multiperiod, multi-echelon integrated forward and reverse supply chain network design problem with transportation mode selection. Different decisions including determination of the optimum number and locations of facilities, facilities' opening time, and transportation mode selection were considered in this paper. Due to the multi-period nature of the problem, the problem is flexible for future periods. A mixed integer nonlinear programming model was proposed for the introduced problem, considering different levels of facility capacities. As another contribution, a genetic algorithm was developed to cope with the problem's complexity, especially for large-sized instances. Effectiveness and reliability of the algorithm, evaluated by solving several random instances with the obtained numerical results and comparisons, confirmed the capability of the proposed algorithm to find good solutions within an acceptable processing time period.
\end{abstract}

(C) 2020 Sharif University of Technology. All rights reserved.

\section{Introduction}

Supply chain configuration has a significant role in the effectiveness of a supply chain. A typical supply chain network is composed of forward and reverse logistics. The forward logistics is utilized to transform

\footnotetext{
*. Corresponding author. Tel.: +98 8733660073 ;

Fax: +98 8733668513

E-mail addresses: Alireza.eydi@uok.ac.ir (A. Eydi); saeed.fazayeli@gmail.com (S. Fazayeli);

ghafouri.indeng@yahoo.com (H. Ghafouri)
}

doi: $10.24200 /$ sci. 2018.5261 .1175 raw material into finished goods before delivering them to the end-users such as suppliers, production centers, and distributors. On the other hand, reverse logistics is composed of collection and inspection centers, recycling centers, disposal centers, and centers for the reproduction of returned goods [1]. In recent years, reverse logistic strategies have been increasingly regarded by researchers. This is because of the residual value of imperfect, out of fashion, or unsold products at the end of the forward supply chain. The other reason behind the importance of such strategies is to reduce or eliminate the waste generation to comply with environmental regulations or other social commitments. 
As such, the reverse logistics has been mainly focused on the management, inspection, and arrangement of the waste in terms of material, part, and product collection/delivery from/to processing or repair centers and tracing their return to other supply chains or markets [2]. An independent design of forward and reverse logistic networks results in suboptimal designs in terms of costs and level of service. Therefore, it has been recommended that the forward and reverse logistic networks be simultaneously designed to achieve a so-called integrated design [1].

In recent years, a great deal of development has been realized within the field of Supply Chain Network Design (SCND); although a great deal of research has been focused on this topic, most studies reported so far have been limited to a single period of time, making them less flexible when dealing with periodic variations. However, supply chain networks are expected to be designed with a multi-period scheme to boost their flexibility and provide a basis for taking advantage of multi-facility networks in multiple periods.

This research is an extension to the forward and reverse SCND problem, wherein a multi-period, multiechelon model is considered. The multi-echelon model helps consider the entire supply chain, while the multiperiod model contributes to better solutions in the long run. The proposed problem can be applied to such products as tires, electrical reusable devices, bottle caps or virtually any product that may be returned by customers for any reason. The forward and reverse logistics network design is essential for (a) cost reduction by reusing products and decreasing environmental pollutions by collecting deteriorated items and (b) for enhancing customers' satisfaction by returning the products that are either not satisfactory from the customers' point of view or no longer used. The proposed model allows decision-makers to account for such parameters as transportation cost, purchase cost, etc. by considering their values in different periods. Another feature highlighted in this research is the transportation mode selection. In reality, there are different transportation modes with different associated costs, delivery time, and safety level, etc. Therefore, the choice of transportation mode affects the performance and responsiveness of a supply chain. In order to minimize the total transportation costs, one should establish a balance between the fixed initial costs and variable costs of transportation among network nodes. Furthermore, owing to its comprehensiveness and generalizability, the proposed model can be applied to many of those goods that are to be shipped to the consumer once they are delivered and reproduced. As another contribution to the literature, the present research formulates an appropriate solving algorithm for the newly introduced problem, with its performance verified by examining numerical examples.
The rest of this paper is organized as follows. Section 2 presents a review of the existing literature. Section 3 focuses on the problem description and mathematical formulation of the model. Section 4 is dedicated to the model validation while setting out an approach to the solving algorithm that is further tested on numerical examples on various sizes. Finally, Section 5 draws some conclusion and elaborates on future trends.

\section{Literature review}

As a strategic decision for supply chain management, SCND plays a significant role in determining the effectiveness, associated costs, and responsiveness of a supply chain. This problem involves facility location, flow allocation, product transportation, inventory and storage management, vehicle routing, etc. Most previous researchers have addressed the designs of forward and reverse logistic networks independently, leading to sub-optimal results. Considering the fact that the reverse logistic network design imposes direct effects on the corresponding forward logistic network, one may suggest the necessity of designing forward and reverse logistic networks together [3]. In this regard, various integrated forward and reverse logistics problems have been defined such as network design, inventory management, capacity management, pricing, and game theory problems.

Different researchers have introduced various problems based on SCND. Lin et al. (2006) [4], Du and Evans (2008) [5], Mehdizadeh et al. (2013) [6], Mirmajlesi and Shafaei (2016) [7], Taleizadeh and Sadeghi (2018) [8], and Fathollahi Fard and HajaghaeiKeshteli (2018) [9] focused on the number of supply chain echelons. Some other researchers such as Badri et al. (2013) [10] and Nobari and Kheirkhah (2018) [11] based their investigations on the number of programming periods. Multi-product systems have also become an eye-catching interest to researchers $[4,10]$. Cardoso et al. (2013) [12], Pedram et al. (2017) [13], and Lieckens and Vandaele (2007) [14] worked on the uncertainties associated with the parameters of such systems. They considered the demand as a source of such uncertainties and modeled it via a scenario treebased approach.

Center capacities (i.e., capacity extension or contraction, addition or elimination of storage facilities, etc.) represent another significant aspect of SCND. For instance, Aghezzaf (2005) [15] and Shaharudin et al. (2017) [16] considered the possibility of expanding the capacity of facilities, while Lowe et al. (2002) [17] proposed a model to design supply chain networks with a reducible capacity. Furthermore, Martel et al. (2006) [18] developed a logistic model wherein the center capacity could be either increased or decreased. 
In another research, Karabakal et al. (2000) [19] analyzed the supply chain across the American branch of Volkswagen Company.

Some researchers have addressed the inventory in the SCND. In the literature on inventory programming, the majority of decisions correspond to the proper location of inventory storage facilities [15,20-22]. Some research studies have considered the inventory storage to be non-reducible to only one echelon [23-25], while some others have focused on the raw material supply and final products storage, e.g., Jang et al. (2002) [23], Melo et al. (2006) [24], Syam (2002) [25], van Weele (2009) [26], and Cordeau et al. (2006) [27]. In another study, Yan et al. (2003) [28] proposed a multi-echelon, multi-product, single-time period model for SCND and raw material supply. Zhou and Chen (2017) [29] considered the inventory control problem for both forward and reverse logistics.

Transportation mode selection has been widely regarded in previous research studies. When it comes to the choice of transportation mode in SCND, either of two cases may arise: (1) a given pair of nodes can be handled by more than one transportation mode [30], (2) only one transportation mode is available between a given pair of nodes [31].

Heydari et al. (2017) [32] and Taleizadeh and Sadeghi (2018) [8] proposed a number of pricing strategies for dealing with competitive reverse supply chains. Giri et al. (2017) [33] and Fathollahi Fard and Hajaghaei-Keshteli (2018) [9] investigated the impacts of cooperation and competition based on game theory. Khakim Habibi et al. (2017) [34] presented a collection-disassembly problem in the reverse supply chain. Butzer et al. (2017) [35] defined a performance measurement system to assess international reverse supply chains. Goh et al. (2007) [36] developed a location programming model for international facilities.

Different researchers have developed a variety of approaches to solving their proposed problems; these can be classified into exact and approximate methods (heuristic and metaheuristic methods). Lu and Bostel (2007) [37] proposed a Lagrangian relaxation method. Üster et al. (2007) [38] employed benders decomposition. Min and Ko (2008) [39], Lee and Chan (2009) [40], Trappey et al. (2010) [41], and Fakhrzad and Moobed (2010) [42] used genetic algorithm. Mehdizadeh et al. (2013) [6] developed a hybrid priority-based genetic algorithm and simulated annealing algorithm. Zegordi et al. (2010) [43] considered a gender-based genetic algorithm, in which two different types of chromosomes with unequal structures were considered. More recently, a number of scholars have adopted new algorithms for such a purpose. In this respect, Modiri-Delshad et al. (2016) [44] used back-tracking search algorithm; Kaboli et al. (2016) [45] proposed an artificial cooperative search algorithm; Rafieerad et al. (2017) [46] applied a multi-objective Particle Swarm Optimization (PSO); Kaboli et al. (2017) [47] introduced rain-fall optimization algorithm; moreover, Kaboli et al. (2017) [48] proposed a gene expression programming for electrical consumption forecasting; Sebtahmadi et al. (2018) [49] used PSO-DQ Current Control Scheme; Mansouri et al. (2012) [50] presented a hybrid neuro-fuzzy- P.I. fed Controller for controlling the rpm of brush-less D.C. motors; Modiri-Delshad et al. (2013) [51] proposed an iterative algorithm for an economic dispatch in a micro grid. They further used the algorithm to address the economic dispatch in a power system.

Given the focus of the present research, i.e., integrated SCND, Amin and Zhang (2013) [1] proposed a multi-objective, multi-echelon, multi-product model that represented a consistent image of integrity across the system. Mirmajlesi and Shafaei (2016) [7] considered a multi-period, multi-product, multi-echelon capacitated supply chain problem for products of a short lifetime.

As a contribution to the forward and reverse logistics problem and to fill in the existing research gap in the literature on SCND, this study develops a deterministic multi-period, multi-echelon model to maximize the overall profit. The model determines the optimum number and locations of facilities, as well as their establishment times. The considered logistics network structure had three echelons in the forward flow and four echelons in the reverse flow. Furthermore, the choice of transportation mode between different nodes (facilities) was considered. The present research is among the rare research studies that combines forward and reverse logistics to address multi-period logistic network design and scheduling simultaneously. This research further considers the choice of transportation mode (with different fixed and variable costs associated with each transportation mode) between the associated nodes, i.e., mathematical programming for minimizing the transportation costs leads to a proportional balance between the transportation costs and the fixed and variable parameters, affecting the chosen transportation mode. Furthermore, given the numerical complexity of the problem, a metaheuristic algorithm was developed to solve the model. Transportation problem concept comprises a common idea within SCND problems. Due to its superior performance for solving similar problems, genetic algorithm was adopted in this paper. Mixing the transportation problem with the genetic algorithm, one can design an effective solver algorithm for problems of larger sizes.

\section{Problem description and modeling}

In order to accurately demonstrate a schematic of the 


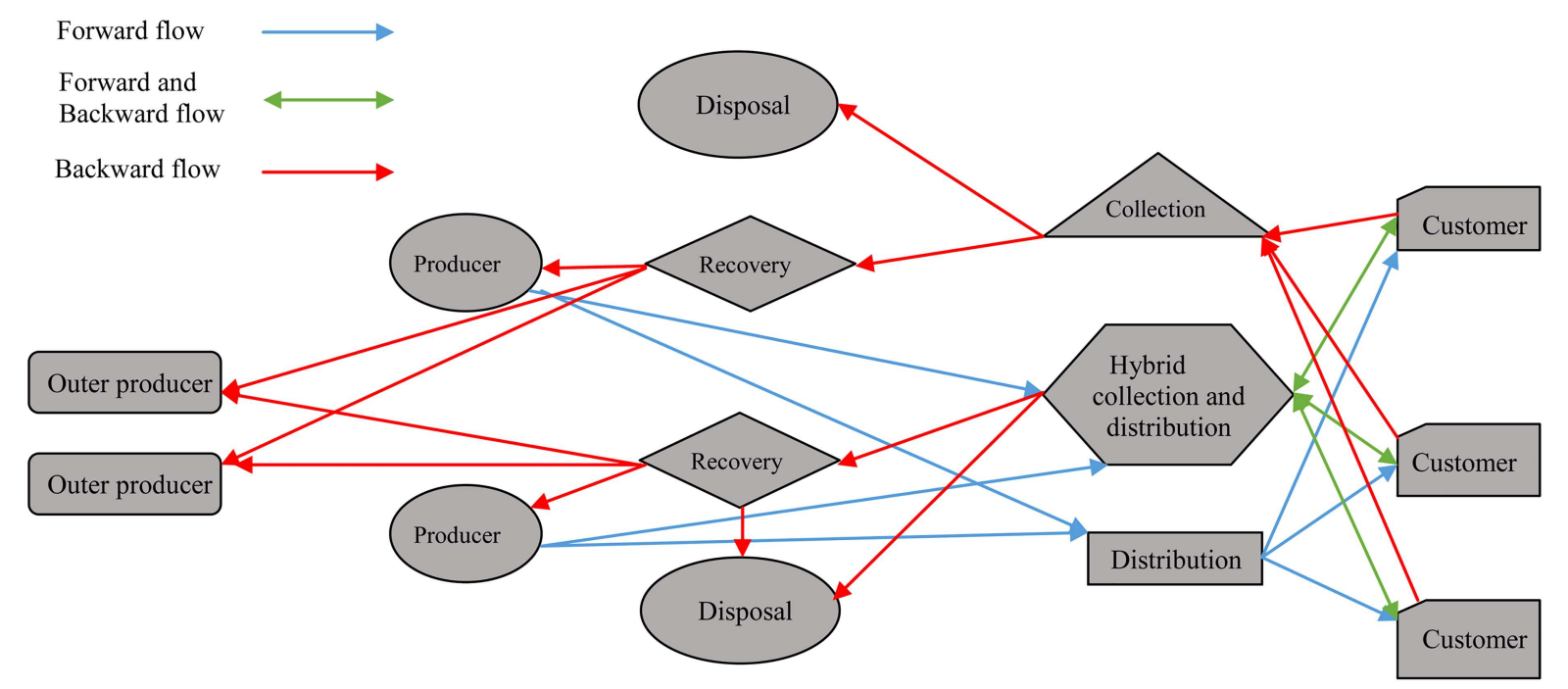

Figure 1. Product distribution and collection diagram.

problem assumptions, Figure 1 provides a diagram view of a forward and reverse integrated supply chain network. Beginning with the chain, following the forward flow, customers' required products are manufactured in production centers before being dispatched to distribution centers from which they are to be delivered to the customers. Such distribution centers are assigned to deliver all of the received products to the customers within the same period of time when the products are received. In terms of tasks and performances, there are two types of distribution centers: normal distribution centers, which are only utilizable along the forward flow and their only task is to receive the products from the distribution centers and forward them to the end-users, and hybrid distribution centers, which are not only capable of accomplishing what normal centers do, but also well set to collect the returned products from the customers at the end of the period in a reverse flow. As end customers, end-users or retailers are placed at the end of the supply chain with their number and locations known within each period. The demand by these customers is known and the chain must necessarily meet the demands in full.

In the reverse flow, products' end-users assume receiving the products from the distribution centers and returning them to the supply chain once the products are consumed. Each customer has his/her specific rate of return. This rate of return can be different in each period. Following the reverse flow, there are collection centers where the returned products from the customers are collected. In this problem, all of returned products must be collected. Normal collection centers can only be utilized along the reverse flow path to collect the returned products from the customers, while hybrid distribution-collection centers can not only accomplish the collecting task, but also perform the distribution task along the forward path flow. Once inspected at the collection centers, the collected products will be sent to the recycling centers if recognized as recyclable; otherwise, the collected products are sent to disposal centers. Different recycling centers may exhibit a different number of recyclable products within each period of time. Once recycled, the collected products either turn into recycled products that can be resold to customers or provide raw material for the production centers. Therefore, the recycled products can be profitable for the chain as they can be sold.

In Figure 1, locating process is performed on the manufacturing, distribution, hybrid distributioncollection, collection, recycling, and disposal facilities within each period so that the demands by the customers can be fulfilled with minimum cost. Various transportation modes are provided for transporting the products between two related facilities. According to the model assumptions, only one transportation mode can be chosen between each pair of nodes until the end of the current period; however, different transportation modes can be utilized for future periods. Each transportation mode has its own fixed and variable costs. Each facility opens at a limited initial capacity so that it cannot serve beyond its initial capacity during the initial period. In this research, expandable capacity was considered, and each level of improvement was associated with some costs imposed on the system; for each facility, the capacity level enhancement was allowed just once per period. The presented model was developed for a single-product system.

\subsection{Mathematical model}

Model sets, indices, parameters, and decision variables are as follows: 
Sets

$v \quad$ Set of fixed locations of outer manufacturers, $v=1,2, \ldots, V$

$i \quad$ Set of potential locations for manufacturing centers, $i=1,2, \ldots, I$

$j \quad$ Set of potential locations for distribution centers, $j=1,2, \ldots, J$

$k \quad$ Set of fixed locations of customers, $k=1,2, \ldots, K$

$l \quad$ Set of potential locations for collection and inspection centers, $l=1,2, \ldots, L$

$h \quad$ Set of potential locations for hybrid distribution-collection centers,

$h=1,2, \ldots, H$

$g \quad$ Set of potential locations for recycling centers, $g=1,2, \ldots, G$

$m \quad$ Set of potential locations for disposal centers, $m=1,2, \ldots, M$

$n \quad$ Set of available capacity levels for facilities, $n=1,2, \ldots, N$

$c \quad$ Set of transport modes between a pair of nodes, $c=1,2, \ldots, C$

$t \quad$ Set of time periods, $t=1,2, \ldots, T$

\section{Parameters}

$D M_{k t} \quad$ The demand by the customer $k$ in time period $t$

$P R_{k t} \quad$ Product's unit price for the customer $k$ in time period $t$

$P R I_{i t} \quad$ Recycled product's unit price for the manufacturing center $i$ in time period $t$

$P R V_{v t} \quad$ Recycled product's unit price for the outer customer $v$ in time period $t$

$P C_{i t} \quad$ Unit production cost at the manufacturing center $i$ in time period $t$

$I C_{l t} \quad$ Unit cost of inspection test at the collection and inspection center $l$ in time period $t$

$I C_{h t} \quad$ Unit cost of inspection test at the hybrid distribution-collection center $h$ in time period $t$

$R C_{g t} \quad$ Unit cost of product recycling at recycling center $g$ in time period $t$

$D C_{m t} \quad$ Unit cost of returned product disposal at disposal center $m$ in time period $t$

$X O_{i t} \quad$ Fixed cost to establish the manufacturing center $i$ in time period $t$, given it was closed at time period $t-1$

$X C_{i t} \quad$ Fixed cost to close the manufacturing center $i$ in time period $t$, given it was open in time period $t-1$
$F E X_{\text {int }} \quad$ Fixed cost to expand the manufacturing center $i$ with the capacity level of $n$ in time period $t$

$Y O_{j t} \quad$ Fixed cost to establish the distribution center $j$ in time period $t$, given it was closed in time period $t-1$

$Y C_{j t} \quad$ Fixed cost to close the distribution center $j$ in time period $t$, given it was open in time period $t-1$

$F E Y_{\text {jnt }} \quad$ Fixed cost to expand the distribution center $j$ with the capacity level of $n$ in time period $t$

$Z O_{l t} \quad$ Fixed cost to establish the collection and inspection center $l$ in time period $t$, given it was closed in time period $t-1$

$Z C_{l t} \quad$ Fixed cost to close the collection and inspection center $l$ in time period $t$, given it was open in time period $t-1$

$F E Z_{l . n t} \quad$ Fixed cost to expand the collection and inspection center $l$ with the capacity level of $n$ in time period $t$

$U O_{m t} \quad$ Fixed cost to establish the disposal center $m$ in time period $t$, given it was closed in time period $t-1$

$U C_{m t} \quad$ Fixed cost to close the disposal center $m$ in time period $t$, given it was open in time period $t-1$

$F E U_{m n t} \quad$ Fixed cost to expand the disposal center $m$ with the capacity level of $n$ in time period $t$

$W O_{h t} \quad$ Fixed cost to establish the hybrid distribution-collection center $h$ in time period $t$, given it was closed in time period $t-1$

$W C_{h t} \quad$ Fixed cost to close the hybrid distribution-collection center $h$ in time period $t$, given it was open in time period $t-1$

FEW $W_{\text {hnt }} \quad$ Fixed cost to expand the hybrid distribution-collection center $h$ with the capacity level of $n$ in time period $t$

$Q O_{g t} \quad$ Fixed cost to establish the recycling center $g$ in time period $t$, given it was closed in time period $t-1$

$Q C_{g t} \quad$ Fixed cost to close the recycling center $g$ in time period $t$, given it was open in time period $t-1$

$F E Q_{g n t} \quad$ Fixed cost to expand the recycling center $g$ with the capacity level of $n$ in time period $t$

$\mathrm{CaI}_{i t} \quad$ Capacity of the manufacturing center $i$ in time period $t$ 
$E C I_{\text {int }} \quad$ Development capacity of the manufacturing center $i$ with the capacity level of $n$ in time period $t$

Ca $J_{j t} \quad$ Capacity of the distribution center $j$ in time period $t$

$E C J_{j n t} \quad$ Development capacity of the distribution center $j$ with the capacity level of $n$ in time period $t$

$\mathrm{CaL}_{l t} \quad$ Capacity of the collection and inspection center $l$ in time period $t$

$E C L_{\text {lnt }} \quad$ Development capacity of the collection and inspection center $l$ with the capacity level of $n$ in time period $t$

$\mathrm{CaH}_{h t} \quad$ Capacity of the hybrid distributioncollection center $h$ in time period $t$

$E C H_{h n t} \quad$ Development capacity of the hybrid distribution-collection center $h$ with the capacity level of $n$ in time period $t$

$\mathrm{Ca} G_{g t} \quad$ Capacity of the recycling center $g$ in time period $t$

$E C G_{\text {gnt }} \quad$ Development capacity of the recycling center $g$ with the capacity level of $n$ in time period $t$

$C a M_{m t} \quad$ Capacity of the disposal center $m$ in time period $t$

$E C M_{m n t}$ Development capacity of the disposal center $m$ with the capacity level of $n$ in time period $t$

$C I J_{i j t c} \quad$ Unit transportation cost from the manufacturing center $i$ to the distribution center $j$ in time period $t$ via transport mode $c$

$F I J_{i j t c} \quad$ Fixed transportation cost from the manufacturing center $i$ to the distribution center $j$ in time period $t$ via transport mode $c$

$C J K_{j k t c} \quad$ Unit transportation cost from the distribution center $j$ to the customer $k$ in time period $t$ via transport mode $c$

$F J K_{j k t c} \quad$ Fixed transportation cost from the distribution center $j$ to the customer $k$ in time period $t$ via transport mode $c$

$C K L_{k l t c} \quad$ Unit transportation cost from the customer $k$ to the collection and inspection center $l$ in time period $t$ via transport mode $c$

$F K L_{k l t c} \quad$ Fixed transportation cost from the customer $k$ to the collection and inspection center $l$ in time period $t$ via transport mode $c$
CHK $K_{\text {hktc }}$ Unit transportation cost from the hybrid distribution-collection center $h$ to the customer $k$ in time period $t$ via transport mode $c$

$F H K_{\text {hktc }}$ Fixed transportation cost from the hybrid distribution-collection center $h$ to the customer $k$ in time period $t$ via transport mode $c$

CIH $H_{\text {ihtc }} \quad$ Unit transportation cost from the manufacturing center $i$ to the hybrid distribution-collection center $\mathrm{h}$ in time period $t$ via transport mode $c$

FIH $H_{\text {ihtc }} \quad$ Fixed transportation cost from the manufacturing center $i$ to the hybrid distribution-collection center $h$ in time period $t$ via transport mode $c$

$C L G_{\text {lgtc }} \quad$ Unit transportation cost from the collection and inspection center $l$ to the recycling center $g$ in time period $t$ via transport mode $c$

$F L G_{l g t c} \quad$ Fixed transportation cost from the collection and inspection center $l$ to the recycling center $g$ in time period $t$ via transport mode $c$

$C L M_{\text {lmtc }}$ Unit transportation cost from the collection and inspection center $l$ to the disposal center $m$ in time period $t$ via transport mode $c$

$F L M_{l m t c}$ Fixed transportation cost from the collection and inspection center $l$ to the disposal center $m$ in time period $t$ via transport mode $c$

CHM $M_{\text {hmtc }}$ Unit transportation cost from the hybrid distribution-collection center $h$ to the disposal center $m$ in time period $t$ via transport mode $c$

FHM $M_{\text {hmtc }}$ Fixed transportation cost from the hybrid distribution-collection center $h$ to the disposal center $m$ in time period $t$ via transport mode $c$

CHG $G_{\text {hgtc }}$ Unit transportation cost from the hybrid distribution-collection center $h$ to the recycling center $g$ in time period $t$ via transport mode $c$

FHG $G_{\text {hgtc }}$ Fixed transportation cost from the hybrid distribution-collection center $h$ to the recycling center $g$ in time period $t$ via transport mode $c$

$C G M_{\text {gmtc }}$ Unit transportation cost from the recycling center $g$ to the disposal center $m$ in time period $t$ via transport mode $c$ 
$F G M_{g m t c}$ Fixed transportation cost from the recycling center $g$ to the disposal center $m$ in time period $t$ via transport mode $c$

$C G I_{\text {gitm }} \quad$ Unit transportation cost from the recycling center $g$ to the manufacturing center $i$ in time period $t$ via transport mode $c_{\text {gitc }}$

$F G I_{\text {gitc }} \quad$ Fixed transportation cost from the recycling center $g$ to the manufacturing center $i$ in time period $t$ via transport mode $c$

$C G V_{\text {gvtc }} \quad$ Unit transportation cost from the recycling center $g$ to the outer customer $v$ in time period $t$ via transport mode $c$

$F G V_{\text {gvtc }}$ Fixed transportation cost from the recycling center $g$ to the outer customer $v$ in time period $t$ via transport mode $c$

$R K_{k} \quad$ Rate of return for the used products by customer $k$

$R I \quad$ Rate of usable material in the collection and hybrid distributioncollection centers

$R G \quad$ Rate of recyclable material at the recycling centers

$D_{j t} \quad$ Unit distribution cost for the distribution center $j$ in time period $t$

$D_{h t} \quad$ Unit distribution cost for the hybrid distribution-collection center $h$ in time period $t$

\section{Non-negative variables}

$Q I J_{i j t} \quad$ The volume of products sent from the manufacturing center $i$ to the distribution center $j$ in time period $t$

$Q J K_{j k t} \quad$ The volume of products sent from the distribution center $j$ to the customer $k$ in time period $t$

$Q I H_{i h t} \quad$ The volume of products sent from the manufacturing center $i$ to the hybrid distribution-collection center $h$ in time period $t$

$Q H K_{h k t} \quad$ The volume of products sent from the hybrid distribution-collection center $h$ to the customer $k$ in time period $t$

$Q K L_{k l t} \quad$ The volume of products sent from the customer $k$ to the collection and inspection center $l$ in time period $t$

$Q K H_{k h t} \quad$ The volume of products sent from the customer $k$ to the hybrid distribution-collection center $h$ in time period $t$
$Q L G_{l g t} \quad$ The volume of products sent from the collection and inspection center $l$ to the recycling center $g$ in time period $t$

$Q L M_{l m t} \quad$ The volume of products sent from the collection and inspection center $l$ to the disposal center $m$ in time period $t$

QH $M_{h m t}$ The volume of products sent from the hybrid distribution-collection center $h$ to the disposal center $m$ in time period $t$

$Q H G_{h g t} \quad$ The volume of products sent from the hybrid distribution-collection center $h$ to the recycling center $g$ in time period $t$

$Q G M_{g m t}$ The volume of products sent from the recycling center $g$ to the disposal center $m$ in time period $t$

$Q G I_{\text {git }} \quad$ The volume of products sent from the recycling center $g$ to the manufacturing center $i$ in time period $t$

$Q G V_{g v t} \quad$ The volume of products sent from the recycling center $g$ to the outer customer $v$ in time period $t$

\section{Binary variables}

$X_{i t} \begin{cases}1: & \text { If the manufacturing center } i \\ & \text { is established in time period } t \\ 0: & \text { Otherwise }\end{cases}$

$E X_{i . n t} \begin{cases}1: & \text { If the manufacturing center } i \\ & \text { is developed with the capacity level of } \\ & n \text { in time period } t \\ 0: \quad & \text { Otherwise }\end{cases}$

$Y_{j t} \begin{cases}1: & \text { If the distribution center } j \\ & \text { is established in time period } t \\ 0: & \text { Otherwise }\end{cases}$

$E Y_{j n t}\left\{\begin{aligned} 1: & \text { If the distribution center } j \\ & \text { is developed with the capacity level of } \\ & n \text { in time period } t \\ 0: & \text { Otherwise }\end{aligned}\right.$

$Z_{l t} \begin{cases}1: & \text { If the collection and inspection center } l \\ & \text { is established in time period } t \\ 0: & \text { Otherwise }\end{cases}$ 
$E Z_{\text {l.nt }}\left\{\begin{aligned} 1: & \text { If the collection and inspection center } l \\ & \text { is developed with the capacity level of } \\ & n \text { in time period } t \\ 0: & \text { Otherwise }\end{aligned}\right.$

$U_{m t} \begin{cases}1: & \text { If the disposal center } m \\ & \text { is established in time period } t \\ 0: & \text { Otherwise }\end{cases}$

$E U_{m n t}\left\{\begin{aligned} 1: \quad & \text { If the disposal center } m \\ & \text { is developed with the capacity level of } n \\ & \text { in time period } t \\ 0: \quad & \text { Otherwise }\end{aligned}\right.$

$W_{h t}\left\{\begin{aligned} 1: & \text { If the hybrid distribution-collection center } \\ & h \text { is established in time period } t \\ 0: & \text { Otherwise }\end{aligned}\right.$

$E W_{h n t}\left\{\begin{aligned} 1: & \text { If the hybrid distribution-collection center } \\ & h \text { is developed with the capacity level of } \\ & n \text { in time period } t \\ 0: \quad & \text { Otherwise }\end{aligned}\right.$

$Q_{g t} \begin{cases}1: & \text { If the recycling center } g \\ & \text { is established in time period } t \\ 0: & \text { Otherwise }\end{cases}$

$E Q_{g n t}\left\{\begin{aligned} 1: \quad & \text { If the recycling center } g \\ & \text { is developed with the capacity level of } \\ & n \text { in time period } t \\ 0: \quad & \text { Otherwise }\end{aligned}\right.$

$I J_{i j t c}\left\{\begin{aligned} 1: & \text { If the transport mode } c \\ & \text { is chosen for the route from } i \\ & \text { to } j \text { in time period } t \\ 0: & \text { Otherwise }\end{aligned}\right.$

$K L_{k l t c}\left\{\begin{aligned} 1: & \text { If the transport mode } c \\ & \text { is chosen for the route from } k \\ & \text { to } l \text { in time period } t \\ 0: & \text { Otherwise }\end{aligned}\right.$

$J K_{j k t c}\left\{\begin{aligned} 1: & \text { If the transport mode } c \\ & \text { is chosen for the route from } j \\ & \text { to } k \text { in time period } t \\ 0: & \text { Otherwise }\end{aligned}\right.$
$H k_{h k t c}\left\{\begin{aligned} 1: & \text { If the transport mode } c \\ & \text { is chosen for the route from } h \\ & \text { to } k \text { in time period } t \\ 0: & \text { Otherwise }\end{aligned}\right.$

$I H_{i h t c}\left\{\begin{aligned} 1: & \text { If the transport mode } c \\ & \text { is chosen for the route from } i \text { to } h \\ & \text { in time period } t \\ 0: & \text { Otherwise }\end{aligned}\right.$

$L G_{l g t c} \begin{cases}1: & \text { If the transport mode } c \\ & \text { is chosen for the route from } l \\ & \text { to } g \text { in time period } t \\ 0: & \text { Otherwise }\end{cases}$

$L M_{l m t c}\left\{\begin{aligned} 1: & \text { If the transport mode } c \\ & \text { is chosen for the route from } l \\ & \text { to } m \text { in time period } t \\ 0: & \text { Otherwise }\end{aligned}\right.$

$H M_{h m t c}\left\{\begin{aligned} 1: & \text { If the transport mode } c \\ & \text { is chosen for the route from } h \\ & \text { to } m \text { in time period } t \\ 0: & \text { Otherwise }\end{aligned}\right.$

$H G_{h g t c}\left\{\begin{aligned} 1: & \text { If the transport mode } c \\ & \text { is chosen for the route from } h \\ & \text { to } g \text { in time period } t \\ 0: & \text { Otherwise }\end{aligned}\right.$

$G M_{g m t c} \begin{cases}1: & \text { If the transport mode } c \\ & \text { is chosen for the route from } g \\ & \text { to } m \text { in time period } t \\ 0: & \text { Otherwise }\end{cases}$

$G I_{\text {gitc }}\left\{\begin{aligned} 1: & \text { If the transport mode } c \\ & \text { is chosen for the route from } g \\ & \text { to } i \text { in time period } t \\ 0: & \text { Otherwise }\end{aligned}\right.$

$G V_{g v t c} \begin{cases}1: \quad & \text { If the transport mode } c \\ & \text { is chosen for the route from } g \\ & \text { to } v \text { in time period } t \\ 0: \quad & \text { Otherwise }\end{cases}$

$K H_{k h t c} \begin{cases}1: & \text { If the transport mode } c \\ & \text { is chosen for the route from } k \\ & \text { to } h \text { in time period } t \\ 0: & \text { Otherwise }\end{cases}$ 
where $M$ is a large number, and RI and RK denote rates of return, can take values between 0 and 1 , and express the fraction of original products that were returned. Based on the assumptions, the parameters and variables of the model are defined, and the objective function, aimed at profit maximization, is formulated as follows:

\section{Objective function and its components}

Maximise Profit $=\sum_{t}\left(\right.$ Income $_{t}-$ Cost $\left._{t}\right)$.

$$
\begin{aligned}
\text { Income }_{t}= & \sum_{j} \sum_{k}\left(Q J K_{j k t}^{*} \mathrm{PR}_{k t}\right) \\
& +\sum_{h} \sum_{k}\left(Q H K_{h k t}^{*} \mathrm{PR}_{k t}\right) \\
& +\sum_{g} \sum_{i}\left(Q G I_{g i t}^{*} \mathrm{PRI}_{i t}\right) \\
& +\sum_{g} \sum_{v}\left(Q G V_{g v t}^{*} \mathrm{PRV}_{v t}\right)
\end{aligned}
$$

Cost $_{t}=\sum_{i} X O_{i t}\left(1-X_{i, t-1}\right) X_{i t}$

$+\sum_{i} X C_{i t}^{*} X_{i, t-1}\left(1-X_{i t}\right)$

$+\sum_{j} Y O_{j t}\left(1-Y_{j, t-1}\right) Y_{j t}$

$+\sum_{j} Y C_{j t}^{*} Y_{j, t-1}\left(1-Y_{j t}\right)$

$+\sum_{l} Z O_{l t}\left(1-Z_{l, t-1}\right) Z_{l t}$

$+\sum_{l} Z C_{l t}^{*} Z_{l, t-1}\left(1-Z_{l t}\right)$

$+\sum_{m} U O_{m t}\left(1-U_{m, t-1}\right) U_{m t}$

$+\sum_{m} U C_{m t}^{*} U_{m, t-1}\left(1-U_{m t}\right)$

$+\sum_{h} W O_{h t}\left(1-W_{h, t-1}\right) W_{i t}$

$+\sum_{h} W C_{h t}^{*} W_{h, t-1}\left(1-W_{h t}\right)$

$+\sum_{g} Q O_{g t}\left(1-Q_{g, t-1}\right) Q_{g t}$ $+\sum_{g} Q C_{g t}^{*} Q_{g, t-1}\left(1-Q_{g t}\right)$

$+\sum_{i} \sum_{n} F E X_{\mathrm{int}}\left(E X_{\mathrm{int}}-E X_{i n, t-1}\right)$

$+\sum_{j} \sum_{n} F E Y_{j n t}\left(E Y_{j n t}-E Y_{j n, t-1}\right)$

$+\sum_{l} \sum_{n} F E Z_{l n t}\left(E Z_{l n t}-E Z_{l n, t-1}\right)$

$+\sum_{m} \sum_{n} F E U_{m n t}\left(E U_{m n t}-E U_{m n, t-1}\right)$

$+\sum_{h} \sum_{n} F E W_{h n t}\left(E W_{h n t}-E W_{i h, t-1}\right)$

$+\sum_{g} \sum_{n} F E Q_{g n t}\left(E Q_{g n t}-E Q_{g n, t-1}\right)$

$+\sum_{i} \sum_{j}\left(Q I J_{i j t}^{*} P C_{i t}\right)+\sum_{i} \sum_{h}\left(Q I H_{i h t}^{*} P C_{i t}\right)$

$+\sum_{j} \sum_{k}\left(Q J K_{j k t}^{*} D_{j t}\right)+\sum_{h} \sum_{k}\left(Q H K_{h k t}^{*} D_{h t}\right)$

$+\sum_{k} \sum_{l}\left(Q K L_{k l t}^{*} I C_{l t}\right)+\sum_{k} \sum_{h}\left(Q K H_{k h t}^{*} I C_{h t}\right)$

$+\sum_{l} \sum_{m}\left(Q L M_{l m t}^{*} D C_{m t}\right)$

$+\sum_{h} \sum_{m}\left(Q H M_{h m t}^{*} D C_{m t}\right)$

$+\sum_{g} \sum_{m}\left(Q G M_{g m t}^{*} D C_{m t}\right)$

$+\sum_{l} \sum_{g}\left(Q L G_{\lg t}^{*} R C_{g t}\right)$

$+\sum_{h} \sum_{g}\left(Q H G_{h g t}^{*} R C_{g t}\right)$

$+\sum_{i} \sum_{j}\left(Q I J_{i j t}^{*}\left(\sum_{c} I J_{i j t c}^{*} C I J_{i j t c}\right)\right)$

$+\sum_{j} \sum_{k}\left(Q J K_{j k t}^{*}\left(\sum_{c} J K_{j k t c}^{*} C J K_{j k t c}\right)\right)$

$+\sum_{k} \sum_{l}\left(Q K L_{k l t}^{*}\left(\sum_{c} K L_{k l t c}^{*} C K L_{k l t c}\right)\right)$ 


$$
\begin{array}{ll}
+\sum_{h} \sum_{k}\left(Q H K_{h k t}^{*}\left(\sum_{c} H K_{h k t c}^{*} C H K_{h k t c}\right)\right) & +\sum_{h} \sum_{m} \sum_{c} H M_{h m t c}^{*} F H M_{h m t c} \\
\sum_{k} \sum_{h}\left(Q K H_{k h t}^{*}\left(\sum_{c} K H_{k h t c}^{*} C K H_{k h t c}\right)\right) & +\sum_{h} \sum_{g} \sum_{c} H G_{h g t c}^{*} F H G_{h g t c} \\
+\sum_{i} \sum_{h}\left(Q I H_{i h t}^{*}\left(\sum_{c} I H_{i h t c}^{*} C I H_{i h t c}\right)\right) & +\sum_{g} \sum_{m} \sum_{c} G M_{g m t c}^{*} F G M_{g m t c} \\
+\sum_{l} \sum_{g}\left(Q L G_{\lg t}^{*}\left(\sum_{c} L G_{\lg t c}^{*} C L G_{\lg t c}\right)\right) & +\sum_{g} \sum_{i} \sum_{c} G I_{g i t c}^{*} F G I_{g i t c} \\
& +\sum_{g} \sum_{v} \sum_{c} G V_{g v t c}^{*} F G V_{g v t c .} .
\end{array}
$$$$
+\sum_{l} \sum_{m}\left(Q L M_{l m t}^{*}\left(\sum_{c} L M_{l m t c}^{*} C L M_{l m t c}\right)\right)
$$$$
+\sum_{h} \sum_{m}\left(Q H M_{h m t}^{*}\left(\sum_{c} H M_{h m t c}^{*} C H M_{h m t c}\right)\right)
$$$$
+\sum_{h} \sum_{g}\left(Q H G_{h g t}^{*}\left(\sum_{c} H G_{h g t c}^{*} C H G_{h g t c}\right)\right)
$$$$
+\sum_{g} \sum_{m}\left(Q G M_{g m t}^{*}\left(\sum_{c} G M_{g m t c}^{*} C G M_{g m t c}\right)\right)
$$$$
+\sum_{g} \sum_{i}\left(Q G I_{g i t}^{*}\left(\sum_{c} G I_{g i t c}^{*} C G I_{\text {gitc }}\right)\right)
$$$$
+\sum_{g} \sum_{v}\left(Q G V_{g v t}^{*}\left(\sum_{c} G V_{g v t c}^{*} C V_{g v t c}\right)\right)
$$$$
+\sum_{i} \sum_{j} \sum_{c} I J_{i j t c}^{*} F I J_{i j t c}
$$$$
+\sum_{j} \sum_{k} \sum_{c} J K_{j k t c}^{*} F J K_{j k t c}
$$$$
+\sum_{k} \sum_{l} \sum_{c} K L_{k l t c}^{*} F K L_{k l t c}
$$$$
+\sum_{h} \sum_{k} \sum_{c} H K_{h k t c}^{*} F H K_{h k t c}
$$$$
+\sum_{i} \sum_{h} \sum_{c} I H_{t c}^{*} F I H_{i h t c}
$$$$
+\sum_{l} \sum_{g} \sum_{c} L G_{l g t c}^{*} F L G_{\lg t c}
$$$$
+\sum_{l} \sum_{m} \sum_{c} L M_{l m t c}^{*} F L M_{l m t c}
$$

The first term of the expression sets out a general form of the objective function. Based on this general form, it is clear that the profit function is obtained to be the difference between the sum of revenues generated along the chain and associated costs. For the sake of simplicity and to obtain a simple mathematical expression, the income function and cost function were expressed as the second and third terms, respectively.

By showing income sources of the chain, the second term of the objective function is composed of two components: (1) the sum of incomes provided by the sale of the finished products to the end-users in the forward flow during various periods, and (2) total incomes raised by selling recycled products to manufacturing centers or external customers during all programming periods.

By reflecting the incurred costs, the third term of the objective function consists of 9 components. For the sake of simplicity, these 9 components are formulated as follows. Component (3.1) denotes total fixed costs associated with the establishment and termination of centers during all periods. Component (3.2) refers to total fixed costs spent on capacity expansion of the centers from the initial capacity to increased capacity levels. Component (3.3) indicates total manufacturing cost spent at the manufacturing centers to fulfill customers' demands within the programming periods. Component (3.4) evaluates the costs incurred upon distributing the products from the distribution or hybrid collection-distribution centers to the end-users. Component (3.5) denotes the total cost incurred to inspect and test the collected returned products; it can be seen as a collection-associated cost. Component (3.6) represents the sum of disposal costs incurred at the disposal centers. Component (3.7) indicates total product recycling costs incurred at the recycling centers. Component (3.8) shows the sum of variable costs of transportation across associated nodes and, finally, Component (3.9) represents the total fixed transportation cost. 
The model constraints:

$\sum_{i} Q I J_{i j t}=\sum_{k} Q J K_{j k t} \quad \forall \mathrm{t}, \mathrm{j}$

$\sum_{j} Q J K_{j k t}+\sum_{h} Q H K_{h k t}=D M_{k t} \quad \forall t, k$,

$\sum_{i} Q I H_{i h t}=\sum_{k} Q H K_{h k t} \quad \forall t, h$,

$\sum_{h} Q K H_{k h t}+\sum_{l} Q K L_{k l t}=D M_{k t}^{*} R K_{k} \quad \forall t, k$,

$R I^{*} \sum_{k} Q K H_{k h t}=\sum_{g} Q H G_{h g t} \quad \forall t, h$,

$(1-R I) \sum_{k} Q K H_{k h t}=\sum_{m} Q H M_{h m t} \quad \forall t, h$,

$R I^{*} \sum_{k} Q K L_{k l t}=\sum_{g} Q L G_{l g t} \quad \forall t, i$,

$(1-R I) \sum_{k} Q K L_{k l t}=\sum_{m} Q L M_{l m t} \quad \forall t, l$,

$R G^{*}\left(\sum_{h} Q H G_{h g t}+\sum_{l} Q L G_{\lg t}\right)$

$=\sum_{v} Q G V_{g v t}+\sum_{i} Q G I_{g i t} \quad \forall t, g$,

$(1-R G)\left(\sum_{h} Q H G_{h g t}+\sum_{l} Q L G_{\lg t}\right)$

$=\sum_{m} Q G M_{g m t} \quad \forall t, g$,

$\sum_{j} Q I J_{i j t}+\sum_{h} Q I H_{i h t} \leq C a I_{i t}^{*} X_{i t}$

$+\sum_{n}\left(E C I_{\mathrm{int}}^{*} E X_{\mathrm{int}}\right) \quad \forall t, i$,

$\sum_{i} Q I J_{i j t} \leq C a J_{j t}^{*} Y_{j t}+\sum_{n}\left(E C J_{j n t}^{*} E Y_{j n t}\right)$

$\forall t, j$,

$\sum_{k} Q K L_{k l t} \leq C a L_{l t}^{*} Z_{l t}+\sum_{n}\left(E C L_{l n t}^{*} E Z_{l n t}\right)$

$\forall t, l$,

$\sum_{i} Q I H_{i h t}+\sum_{k} Q K H_{k h t} \leq C a H_{h t}^{*} W_{h t}$

$+\sum_{n}\left(E C H_{h n t}^{*} E W_{h n t}\right) \quad \forall t, h$,

$$
\begin{aligned}
\sum_{l} Q L G_{\lg t} & +\sum_{h} Q H G_{h g t} \leq C a G_{g t}^{*} Q_{g t} \\
& +\sum_{n}\left(E C G_{g n t}^{*} E Q_{g n t}\right) \quad \forall t, g, \\
\sum_{l} Q L M_{l m t} & +\sum_{h} Q H M_{h m t}+\sum_{g} Q G M_{g m t} \\
& \leq C a M_{m t}^{*} U_{m t} \\
& +\left(\sum_{n} E C M_{m n t}^{*} E U_{m n t}\right) \quad \forall t, m,
\end{aligned}
$$

$\sum_{n} E X_{i n t} \leq X_{i t} \quad \forall t, i$,

$\sum_{n} E Y_{J n t} \leq Y_{j t} \quad \forall t, j$,

$\sum_{n} E Z_{l n t} \leq Z_{l t} \quad \forall t, l$,

$\sum_{n} E U_{m n t} \leq U_{m t} \quad \forall t, m$,

$\sum_{n} E Q_{g n t} \leq Q_{g t} \quad \forall t, g$,

$\sum_{n} E W_{h n t} \leq W_{h t} \quad \forall t, h$,

$E X_{i n, t-1} \leq E X_{\mathrm{int}} \quad \forall t, n, i$,

$E Y_{j n, t-1} \leq E Y_{j n t} \quad \forall t, n, j$,

$E Z_{l n, t-1} \leq E Z_{l n t} \quad \forall t, n, l$,

$E U_{m n, t-1} \leq E U_{m n t} \quad \forall t, n, m$,

$E Q_{g n, t-1} \leq E Q_{g n t} \quad \forall t, n, g$,

$E W_{h n, t-1} \leq E W_{h n t} \quad \forall t, n, h$,

$\sum_{c} I J_{i j t c} \leq 1 \quad \forall t, i, j$,

$\sum_{c} J K_{j k t c} \leq 1 \quad \forall t, j, k$,

$\sum_{c} K L_{k l t c} \leq 1 \quad \forall t, k, l$,

$\sum_{c} H K_{h k t c} \leq 1 \quad \forall t, h, k$,

$\sum_{c} I H_{i h t c} \leq 1 \quad \forall t, i, h$, 
$\sum_{c} L G_{\lg t c} \leq 1 \quad \forall t, l, g$

$\sum_{c} L M_{l m t c} \leq 1 \quad \forall t, l, m$

$\sum_{c} H M_{h m t c} \leq 1 \quad \forall t, h, m$,

$\sum_{c} G M_{g m t c} \leq 1 \quad \forall t, g, m$,

$\sum_{c} H G_{h g t c} \leq 1 \quad \forall t, h, g$,

$\sum_{c} G I_{g i t c} \leq 1 \quad \forall t, g, i$,

$\sum_{c} G V_{g v t c} \leq 1 \quad \forall t, g, v$,

$\sum_{c} K H_{k h t c} \leq 1 \quad \forall t, h, k$,

$Q I J_{i j t} \leq M \sum_{c} I J_{i j t c} \quad \forall t, i, j$,

$Q J K_{j k t} \leq M \sum_{c} J K_{j k t c} \quad \forall t, j, k$,

$Q K L_{k l t} \leq M \sum_{c} K L_{k l t c} \quad \forall t, k, l$,

$Q H K_{h k t} \leq M \sum_{c} H K_{h k t c} \quad \forall t, h, k$,

$Q I H_{i h t} \leq M \sum_{c} I H_{i h t c} \quad \forall t, i, h$,

$Q L G_{\lg t} \leq M \sum_{c} L G_{\lg t c} \quad \forall t, l, g$,

$Q L M_{l m t} \leq M \sum_{c} L M_{l m t c} \quad \forall t, l, m$,

$Q H M_{h m t} \leq M \sum_{c} H M_{h m t c} \quad \forall t, h, m$,

$Q H G_{h g t} \leq M \sum_{c} H G_{h g t c} \quad \forall t, h, g$,

$Q G M_{g m t} \leq M \sum_{c} G M_{g m t c} \quad \forall t, g, m$,

$Q G I_{g i t} \leq M \sum_{c} G I_{g i t c} \quad \forall t, g, i$,

$Q G V_{g v t} \leq M \sum_{c} G V_{g v t c} \quad \forall t, g, v$,

$Q K H_{k h t} \leq M \sum_{c} K H_{k h t c} \quad \forall t, k, h$,

$$
\begin{gathered}
X_{i t}, E X_{i n t}, Y_{j t}, E Y_{j n t}, Z_{l t}, E Z_{\ln t}, U_{m t}, E U_{m n t}, \\
Q_{g t}, E Q_{g n t}, W_{h t}, E W_{h n t}, I J_{i j t c}, J K_{j k t c}, \\
K L_{k l t c}, H K_{h k t c}, I H_{i h t c}, L G_{\lg t c}, L M_{l m t c}, \\
H M_{h m t c}, H G_{h g t c}, G M_{g m t c}, G I_{g i t c}, G V_{g v t c}, \\
K H_{k h t c} \in\{0,1\} \\
\forall i, j, k, l, h, g, m, v, n, c, t \\
Q I J_{i j t}, Q J K_{j k t}, Q I H_{i h t}, Q H K_{h k t}, Q K L_{k l t}, \\
Q K H_{k h t}, Q L G_{\lg t}, Q L M_{l m t}, Q H M_{h m t}, \\
Q H G_{h g t}, Q G M_{g m t}, Q G I_{g i t}, Q G V_{g v t} \geq 0 \\
\forall i, j, k, l, h, g, m, v, t .
\end{gathered}
$$

Constraints (4)-(6) ensure flow equilibrium within the related nodes to the forward flow path, while Constraints (7)-(13) ensure flow equilibrium within those along the reverse flow path. For the purpose of this paper, flow equilibrium implies the state of equality between the sum of products received and dispatched by a particular node. Constraints (14)(19) define the capacity limitations at different centers. Once opened, each center can operate at its initial capacity only unless a capacity expansion process is undertaken for that center. Constraints (20)-(25) ensure that a capacity expansion can solely be realized for the centers established in the corresponding period. Constraints (26)-(31) introduce the impossibility of a capacity reduction to occur in capacity-expanded facilities, i.e., once the capacity of a facility expands in a given period of time, it cannot be either reduced or returned back to the initial capacity within the same period of time. Constraints (32)-(44) prove that there is only one transportation mode between each pair of nodes during each period of time. Constraints (45)-(57) ensure that no product can be transported between a pair of nodes unless a transportation mode is chosen. Finally, Constraints (58) and (59) imply that the variables shall be non-negative and binary, respectively.

\section{Model validation and solution approach}

In this research, in order to solve small- to mediumsized problems, optimization software called GAMS v.24.2.2 was used without configuring a particular algorithm. The results obtained by this software were used as a reference to compare other solution methods and algorithms. All case studies were processed on a laptop powered by an Intel ${ }^{\circledR} \mathrm{Core}^{\mathrm{TM}} 2$ Dou CPU 
operating at $2.4 \mathrm{GHz}$ and further equipped with $4 \mathrm{~GB}$ of RAM.

By utilizing GAMS software, two important issues were analyzed: the value of $M$ (an adequately large number) and the choice of the solver. Due to the non-linear nature of the mathematical model, BARON solver was employed to solve the illustrative problems. Furthermore, in order to investigate the sensitivity of this solver to the value of $M$, a set of experiments was designed, whose results were analyzed. According to the analyses, the minimum value of $M$ before the problem turns infeasible or unjustified is the maximum value of total demands in different periods. Following this approach, the variable ranges were limited to contract the solution space for the solver so as to accelerate the process of finding the optimum solution.

Having introduced various local techniques to analyze supply chain networks, Krarup and Pruzan (1983) investigated the issues associated with the behavior of such techniques for large-sized problems [52], and proved that the SCND problems were NP-hard. Therefore, for each mathematical model developed for such problems, it is required to present an appropriate algorithm fitted to the problem structure. In order to prove that the processing time increases with the problem size, several purposive cases were designed with different sizes and, then, solved by GAMS software. Table 1 reports the obtained processing times. The table makes it clear that an increase in the number of periods adds to the processing time dramatically.

In Table 1, the first 4-digit part of the code indicates, from left to right, the number of manufacturing centers, the number of distribution centers, the number of hybrid collection-distribution centers, and the number of customers, respectively. The second 4digit part shows, again from left to right, the number of collection centers, the number of recycling centers, the number of disposal centers, and the number of external customers, respectively. Finally, the third part denotes, from left to right, the number of capacity levels, the number of transportation modes between two related nodes, and the number of programming periods. It is worth mentioning that the parameters in the designed illustrative cases have all been set randomly.

\subsection{Solving approach}

Genetic algorithm is among the widely used algorithms for solving NP-hard problems. It is applicable to problems with large feasible spaces. Furthermore, it is particularly helpful for complex problems where the influences of constraints and parameters are unknown. This method enjoys a lower probability of getting trapped in local optimum, as compared to similar techniques. The capability of GA to reach nearoptimum solutions has widened the scope of its application to large-sized problems. It is a nature-inspired and population-based method with a capability to cope with the problems of special structure and is considered in this research because of its ability to find near-optimum solutions and its flexibility to solve a wide range of problems. This is the reason why this algorithm has been selected from a pool of various solving approaches. Furthermore, new chromosomes were proposed here to encode the problem. GA has been previously used to solve reverse logistics problems by some researchers, e.g., Min and Ko (2008) [39], Lee and Chan (2009) [40], Trappey et al. (2010) [41], and Fakhrzad and Moobed (2010) [42]. Accordingly, genetic algorithm was used to solve the problem in this research.

\subsection{Algorithm components}

Components of the algorithm used in this study are described in this subsection.

\subsubsection{Initiator operator and solution demonstration}

In this research, common methods in transportation problems were used to present the solution. The number of products transported from manufacturers to customers was organized into a matrix. As mentioned previously, there is no direct transportation between manufacturers and customers, and the matrix merely shows the origin of the received products. Another feature of the model is the time periods. For each time period, two matrices were used: one for forward

Table 1. Results of solving the illustrative cases.

\begin{tabular}{|c|c|c|c|c|c|c|c|}
\hline \multicolumn{2}{|c|}{ Problem } & \multirow[b]{2}{*}{$\begin{array}{c}\text { Processing } \\
\text { time } \\
\text { (seconds) }\end{array}$} & \multirow[b]{2}{*}{$\begin{array}{c}\text { Objective } \\
\text { function } \\
\text { value } \\
\end{array}$} & \multicolumn{2}{|c|}{ Problem } & \multirow[b]{2}{*}{$\begin{array}{c}\text { Processing } \\
\text { time } \\
\text { (seconds) }\end{array}$} & \multirow[b]{2}{*}{$\begin{array}{c}\text { Objective } \\
\text { function } \\
\text { value }\end{array}$} \\
\hline $\begin{array}{c}\text { Number of } \\
\text { periods }\end{array}$ & Group code & & & $\begin{array}{c}\text { Number of } \\
\text { periods }\end{array}$ & Group code & & \\
\hline \multirow{2}{*}{$T=1$} & $2112-2222-121$ & 2 & 193246 & \multirow{2}{*}{$T=3$} & 2112-2222-123 & 3220 & 735079 \\
\hline & $2212-2223-121$ & 6 & 187956 & & $2113-2223-123$ & 323 & 1629623 \\
\hline \multirow{2}{*}{$T=2$} & $2112-2222-122$ & 70 & 489659 & $T=4$ & $2112-2222-124$ & 14400 & 933059 \\
\hline & $3112-2222-222$ & 158 & 484262 & & & & \\
\hline
\end{tabular}


logistics and another for reverse logistics. In terms of capacities, if the sum of demands in one period exceeds the capacity of facilities, the capacity increases until the entire volume of demands is addressed.

In each period, the number of products shipped from the manufacturing centers to the customers is expressed in terms of a transportation matrix shown below; therefore, each period corresponds to a transportation matrix. Transportation matrices can be seen as chromosomes in this algorithm. In other words, the solution of each period can be seen as two transportation matrices: one for the forward flow path and another for the reverse one:

$$
X_{p}=\left[\begin{array}{cccc}
x_{11} & x_{12} & \ldots & x_{1 n} \\
x_{21} & x_{22} & \ldots & x_{2 n} \\
\ldots & \ldots & \ldots & \ldots \\
x_{m 1} & x_{m 2} & \ldots & x_{m n}
\end{array}\right],
$$

in which rows and columns represent the manufacturing centers and customers, respectively.

The following pseudo-code was used to form the above matrix:

1. Form a set, $T$, including the set of numbers from 1 to $m n$.

2. Randomly choose a number, $k$, from the set $T$.

3. Through the following relationship, extract the row number and column number corresponding to $k$ :

$$
\begin{aligned}
& \text { Row number }(i)=[((k-1) / n)+1] \\
& \text { Column number }(j)=((k-1) / \bmod n)+1 .
\end{aligned}
$$

4. Choose the minimum value across the production values in the $i$ th row and the demand in the $j$ th column and name it $x_{i j}$.

5. Subtract $x_{i j}$ from the production in the $i$ th row and the demand in the $j$ th column.

6. Eliminate $k$ from the set $T$.

7. Repeat the process until all members in $T$ are eliminated.

Once the above matrix was formed, in order to determine the volume of products shipped to customers, each $x_{i j}$ value was randomly decomposed into two parts: the volume of products sent to the distribution centers and that to hybrid distribution-collection centers. Following the process of chromosome formation, one can determine the required quantity of products to be redistributed among the facilities along the reverse flow to reach a complete solution after applying the rate of product return by customers. After applying the rate of product recycling at collection and hybrid centers and determining the number of pushed products toward the recycling and disposal centers (similar to what was done before), the transportation matrix was randomly allocated between two nodes; finally, volumes of the products sent to recycling centers, manufacturers, and external customers were determined by the same approach.

\subsubsection{Crossover operator}

The following pseudocode was used to apply the crossover operator once the parents (matrices) were selected as $X_{1}=\left(x_{i j}^{1}\right)$ and $X_{2}=\left(x_{i j}^{2}\right)$ :

1. Use the following method to define the matrices $D=\left(d_{i j}\right)$ and $R=\left(r_{i j}\right)$.

$$
d_{i j}=\left[\left(x_{i j}^{1}+x_{i j}^{2}\right) / 2\right], \quad r_{i j}=\left(x_{i j}^{1}+x_{i j}^{2}\right) \bmod 2 .
$$

2. Divide the matrix $R$ into two matrices of $R_{1}=\left(r_{i j}^{1}\right)$ and $R_{2}=\left(r_{i j}^{2}\right)$ :

$$
\begin{aligned}
& R=R_{1}+R_{2}, \\
& \sum_{j=1}^{n} r_{i j}^{1}=\sum_{j=1}^{n} r_{i j}^{2}=\frac{1}{2} \sum_{j=1}^{n} r_{i j} \quad i=1,2, \ldots, m, \\
& \sum_{i=1}^{m} r_{i j}^{1}=\sum_{i=1}^{m} r_{i j}^{2}=\frac{1}{2} \sum_{i=1}^{m} r_{i j} \quad j=1,2, \ldots, n .
\end{aligned}
$$

3. Form the offspring $X_{1}^{\prime}$ and $X_{2}^{\prime}$ as follows:

$$
X_{1}^{\prime}=D+R_{1}, \quad X_{2}^{\prime}=D+R_{2} .
$$

\subsubsection{Mutation operator}

In order to apply this operator when a transportation matrix is selected, first, a number of rows and columns are randomly selected within the matrix. In the developed submatrix, the existing values are manipulated, such that the sum of values within each row and column remains unchanged. For instance, assume the following matrix to be subjected to the mutation operator:

\begin{tabular}{|l|l|l|l|l|}
\multicolumn{5}{|c}{ Parent X } \\
\hline 0 & 0 & 5 & 0 & 3 \\
\hline 0 & 4 & 0 & 0 & 0 \\
\hline 0 & 0 & 5 & 7 & 0 \\
\hline 3 & 1 & 0 & 0 & 2 \\
\hline
\end{tabular}

Suppose that the 2nd and 4th rows and the 2nd, 3rd, and 5th columns are selected randomly; this submatrix can be manipulated in the following to meet the mentioned condition:

The selected
matrix \begin{tabular}{|l|l|l|l|l|l|l|} 
The manipulated \\
matric
\end{tabular}

Consequently, the following offspring will result from the mutation operator: 


Offspring
\begin{tabular}{|l|l|l|l|l|}
\hline 0 & 0 & 5 & 0 & 3 \\
\hline 0 & 2 & 0 & 0 & 2 \\
\hline 0 & 0 & 5 & 7 & 0 \\
\hline 2 & 3 & 0 & 0 & 0 \\
\hline
\end{tabular}

\subsubsection{Fitness function}

Fitness function is exactly the same as the problem's objective function, i.e., to maximize the overall profit generated along the chain. This function calculates the incurred costs and gained income along the chain and returns the fitness value for each chromosome. As a maximization function, there is no need to modify the objective function.

\subsubsection{Selection mechanisms}

Two mechanisms were employed to perform the selection task in the proposed algorithm: the roulette wheel and tournament mechanisms. The designed algorithm was configured in such a way that, for each round of selection, $50 \%$ of the parents were selected by the roulette wheel mechanism, while the other $50 \%$ were selected according to the tournament approach.

\subsubsection{Termination criterion}

For the considered algorithm in this research, the termination criterion was set as reaching a limited number of iterations and generation number.

\subsection{Setting the GA parameters}

In order to set the parameters of the genetic algorithm, a sample problem was designed and, then, solved using the considered algorithm in MATLAB software. In the next step, for each parameter within the GA, a set of predefined discrete values (reported in Table 2) was assumed and the problem was solved. Figure 2 shows the contributions of crossover parameter variations in the objective function value when other parameters are kept unchanged. As is observed, the objective function is maximal when the crossover parameter takes a value of 0.8. Further, Figure 3 depicts the contribution of variations in the mutation parameter at another level of mutation parameter; finally, Figure 4 considers the contributions of mutation parameter variations in the objective function value when other parameters are kept unchanged.

The proposed genetic algorithm encompasses five operating parameters. Considering the number and

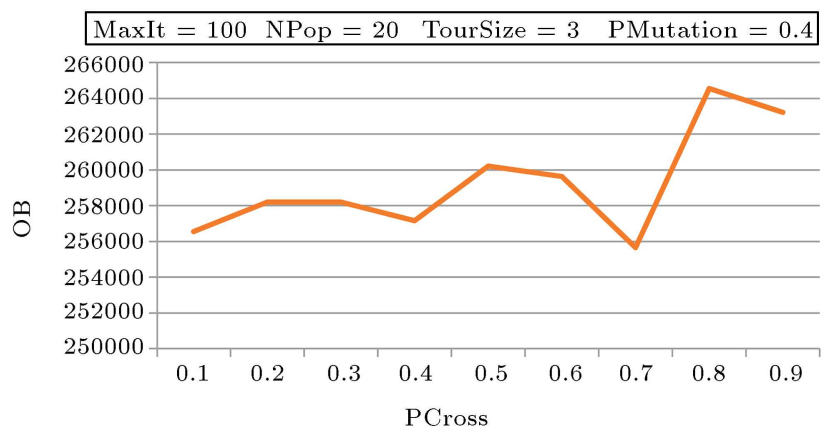

Figure 2. Plot of variations in mutation level 1.

\begin{tabular}{llll} 
MaxIt $=100$ & NPop $=20$ & TourSize $=3$ & PCross $=0.5$ \\
\hline
\end{tabular}

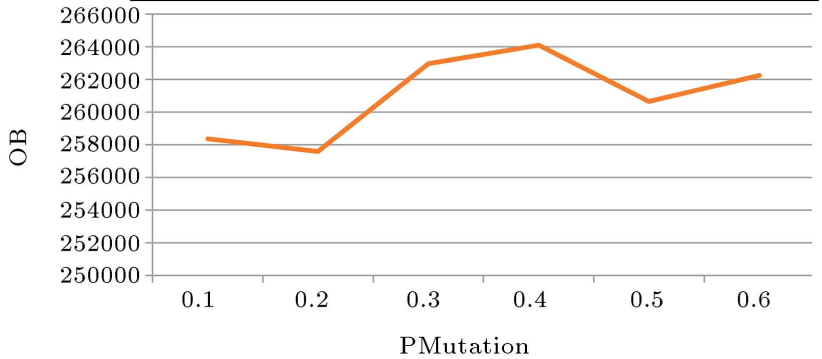

Figure 3. Plot of variations in mutation level 2.

MaxIt $=100 \quad$ NPop $=20 \quad$ TourSize $=3 \quad$ PCross $=0.8$

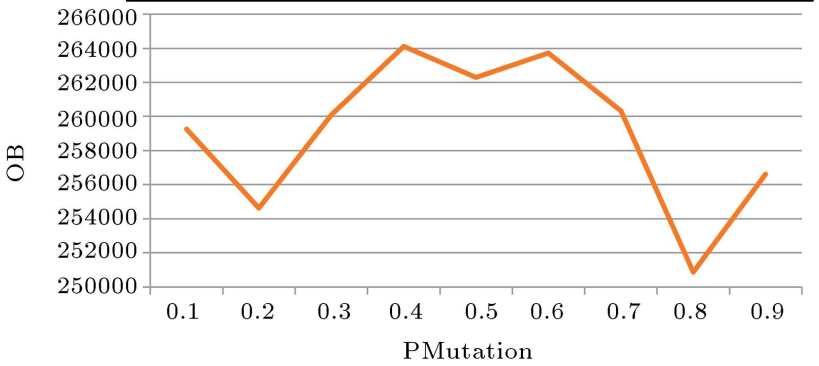

Figure 4. Plot of variations in crossover parameter.

levels of parameters at which each parameter is to be analyzed, one may conclude that it is impossible to consider the contributions of variations in each and any parameter, as well as interactions between the parameters. Therefore, based on the principles of the design of experiments, instead of performing each and every experimental effort, only 80 tests were considered (including single and coupled ones) to look into the effect of such variations on the fitness function.

Table 2. Different levels of Genetic Algorithm (GA) parameters.

\begin{tabular}{ccc}
\hline Parameter & Number of levels & Value \\
\hline Maximum number of iterations & 10 & 400 \\
Population size & 10 & 60 \\
Crossover rate & 9 & 0.8 \\
Mutation rate & 9 & 0.4 \\
Tournament selection size & 5 & 4 \\
\hline
\end{tabular}


Reported in Table 2 are the GA parameters, the number of investigated levels, and the values obtained.

\subsection{Generating cases studies and setting the parameters}

Most of the problems used for numerical tests investigated in the literature on SCND have been randomly generated. Accordingly, in this research, problem data were randomly generated using uniform distribution in certain domains. Considering the number of parameters in the model, no comprehensive reference could be found for benchmarking the parameters; thus, some of the parameters were generated randomly. Therefore, the parameters were generated with reference to Olivares-Benitez et al. (2010) as a valid reference [31]. Furthermore, the problem size was assessed based on two criteria: number of periods and programming number for each problem (Table 3 ).

For each problem, the programming number is equal to the sum of indices, i.e., the sum of digits in the corresponding group code, which can be calculated via the following formula:

$$
P N=i+j+h+k+l+g+m+v+n+c+t .
$$

In Table 4, all details of the problem can be observed. Furthermore, the information regarding the exact mathematical solution of GAMS software is presented in this table.

Presumably, an increase in the time period of the problem adds to the problem complexity and processing time, and the number of recycling centers affects the complexity of the problem. The designed numerical examples were used to analyze these assumptions. Each problem was designated by a two-digit number, with the first digit from the left indicating the number of periods in the problem and the other digit reflecting the number of problems within the corresponding period. Regarding the problem type, an attempt was made to incorporate as many combinations as possible in each period. Average processing times for the two-period and three-period problems were found to be 136 and 2863 seconds, respectively. As expected, the processing time increased by 21 folds when the value of $T$ changed from 2 to 3 . Comparing the processing times obtained for problems 3.1 and 3.4 shown in Table 4, one can easily find that processing time became doubled when the value of $m$ index (number of recycling centers) changed from 1 to 2 . These two comparisons reveal the effect of the parameter $T$ on the sample problem processing time. Furthermore, this table may confirm the performance of the introduced sizing criterion for the sample problems.

In problem 3.1, the processing time was $7200 \mathrm{sec}-$ onds, i.e., the GAMS was not able to solve the problem in 2 hours and the reported objective value was merely the best integer solution found after 2 hours of running the software. This problem number shows that, in particular numerical examples, especially large ones, the software cannot solve the problem at an acceptable time interval; therefore, alternative approaches are needed.

Following the research, some sample problems were solved with genetic algorithm. To do so, first of all, the parameters of each exactly solved problem were fitted into the structure of metaheuristic algorithm so as to establish the same conditions. Subsequently, the

Table 3. Sample problem size assessment.

\begin{tabular}{cccccc}
\hline \multirow{2}{*}{ Size } & \multicolumn{2}{c}{ Problem } & & \multicolumn{2}{c}{ Problem } \\
\cline { 2 - 3 } \cline { 5 - 6 } & $\begin{array}{c}\text { Number of } \\
\text { periods }\end{array}$ & $\begin{array}{c}\text { Programming } \\
\text { number }\end{array}$ & Size & $\begin{array}{c}\text { Number of } \\
\text { periods }\end{array}$ & $\begin{array}{c}\text { Programming } \\
\text { number }\end{array}$ \\
\hline Small & 1 & Any number & Large & 2 & Greater than or equal 18 \\
Medium & 2 & Lower than 18 & Large & 3 & Any number \\
\hline
\end{tabular}

Table 4. Solutions of two-period and three-period sample problems as obtained by GAMS software.

\begin{tabular}{|c|c|c|c|c|c|c|c|}
\hline $\begin{array}{c}\text { Example } \\
\text { number }\end{array}$ & Group code & $\begin{array}{c}\text { Solve } \\
\text { time }\end{array}$ & $\begin{array}{l}\text { Objective } \\
\text { function } \\
\text { value }\end{array}$ & $\begin{array}{c}\text { Example } \\
\text { number }\end{array}$ & $\begin{array}{c}\text { Group } \\
\text { code }\end{array}$ & $\begin{array}{c}\text { Solve } \\
\text { time }\end{array}$ & $\begin{array}{c}\text { Objective } \\
\text { function } \\
\text { value }\end{array}$ \\
\hline 3.1 & $2113-1221-123$ & 7200 & 556462 & 2.1 & $2113-1221-122$ & 74 & 1179640 \\
\hline 3.2 & $1113-1221-123$ & 950 & 520647 & 2.2 & $3113-1221-122$ & 133 & 1057865 \\
\hline 3.3 & $2113-1121-123$ & 2157 & 726932 & 2.3 & $3113-1231-122$ & 282 & 691155 \\
\hline 3.4 & $2113-1211-123$ & 3850 & 916650 & 2.4 & $3113-1331-122$ & 86 & 386833 \\
\hline 3.5 & $1113-1111-123$ & 160 & 1022315 & 2.5 & $3212-1331-122$ & 105 & 538735 \\
\hline \multicolumn{2}{|c|}{$\begin{array}{c}\text { Average solution time for } \\
\text { a three-period case }\end{array}$} & \multicolumn{2}{|r|}{2863} & \multicolumn{2}{|c|}{$\begin{array}{l}\text { Average solution time for } \\
\text { a two-period case }\end{array}$} & \multicolumn{2}{|r|}{136} \\
\hline
\end{tabular}


sample problems were tested in both GAMS (as the exact solution) and MATLAB (as the heuristic solution). In order to reduce the randomness effect of the solving algorithm and prevent it from getting trapped within poor solutions, each sample was launched in MATLAB five times and the obtained results were averaged before being reported as the final result. Table 5 reports the information about each sample.

The processing times were reported in seconds. Table 6 represents a summary of the above table together with analytical results. Shown in this table are the average values for each sample problem, standard deviation within the results obtained for each sample, and the gap between the average solution and exact solution for each sample. The gap was calculated by dividing the difference between the exact and approximate solutions by the exact one. Taking a quick look at this table, one may find that the gap values were generally lower for two-period problems rather than the three-period ones. Considering the gap values for the two-period and three-period problems, it is observed that the value of the gap slightly increases by just $2 \%$ when the parameter $T$ changes from 2 to 3 . This is while, as mentioned before, such a change in parameter

Table 5. Values of the objective function and processing times for sample problems used with the solving algorithm.

\begin{tabular}{|c|c|c|c|c|c|c|c|c|c|c|c|c|c|}
\hline Instance & $\begin{array}{c}\text { Iteration } \\
\text { number }\end{array}$ & 1 & 2 & 3 & 4 & 5 & Instance & $\begin{array}{c}\text { Iteration } \\
\text { number }\end{array}$ & 1 & 2 & 3 & 4 & 5 \\
\hline \multirow{2}{*}{3.1} & Solution & 475375 & 476684 & 487625 & 489297 & 488839 & \multirow{2}{*}{2.1} & Solution & 934420 & 930074 & 950265 & 944300 & 948471 \\
\hline & Time & 182 & 311 & 232 & 252 & 211 & & Time & 19 & 16 & 17 & 24 & 18 \\
\hline \multirow{2}{*}{3.2} & Solution & 441857 & 451536 & 450551 & 439688 & 446045 & \multirow{2}{*}{2.2} & Solution & 920390 & 924900 & 914044 & 937830 & 918110 \\
\hline & Time & 201 & 179 & 175 & 185 & 197 & & Time & 18 & 19 & 18 & 18 & 21 \\
\hline \multirow{2}{*}{3.3} & Solution & 649945 & 653505 & 644582 & 654642 & 646721 & \multirow{2}{*}{2.3} & Solution & 621060 & 631960 & 616550 & 609310 & 624950 \\
\hline & Time & 173 & 194 & 245 & 188 & 189 & & Time & 19 & 19 & 16 & 20 & 20 \\
\hline \multirow{2}{*}{3.4} & Solution & 765027 & 791046 & 762100 & 787237 & 781247 & \multirow{2}{*}{2.4} & Solution & 328980 & 336650 & 340090 & 345040 & 322150 \\
\hline & Time & 173 & 213 & 175 & 263 & 214 & & Time & 19 & 21 & 18 & 22 & 18 \\
\hline \multirow{2}{*}{3.5} & Solution & 793794 & 771966 & 805189 & 805266 & 799156 & \multirow{2}{*}{2.5} & Solution & 510835 & 502625 & 520040 & 503920 & 511390 \\
\hline & Time & 176 & 183 & 182 & 185 & 222 & & Time & 18 & 22 & 18 & 20 & 19 \\
\hline
\end{tabular}

Table 6. A comparison between the results of exact and metaheuristic solutions.

\begin{tabular}{cccccc}
\hline $\begin{array}{c}\text { Instance } \\
\text { number }\end{array}$ & $\begin{array}{c}\text { GAMS } \\
\text { output }\end{array}$ & $\begin{array}{c}\text { Average of } \\
\text { MATLAB } \\
\text { outputs }\end{array}$ & $\begin{array}{c}\text { Standard } \\
\text { deviation of } \\
\text { MATLAB outputs }\end{array}$ & $\begin{array}{c}\text { MATLAB and } \\
\text { GAMS outputs } \\
\text { gap }\end{array}$ & $\begin{array}{c}\text { Average gap } \\
\text { (\%) }\end{array}$ \\
\hline 3.1 & 556462 & 483564 & 6027 & 13.10 & \\
3.2 & 520647 & 445935 & 4130 & 14.34 & 15.09 \\
3.3 & 726932 & 649879 & 3382 & 10.59 & \\
3.4 & 916650 & 777331 & 11014 & 15.19 & \\
3.5 & 1022315 & 795074 & 9755 & 22.22 & \\
& & & & & \\
2.1 & 1179640 & 941506 & 7407 & 12.40 \\
2.2 & 1057865 & 923054 & 6648 & 10.18 & \\
2.3 & 691155 & 620766 & 6268 & 13.50 & \\
2.4 & 386833 & 334582 & 7213 & 5.37 & Average total gap \\
2.5 & 538735 & 509762 & 5191 & & $\mathbf{1 3 . 7 4}$ \\
\hline
\end{tabular}


Table 7. Results of robustness analysis of the proposed metaheuristic algorithm.

\begin{tabular}{cccccc}
\hline $\begin{array}{c}\text { Example } \\
\text { number }\end{array}$ & $\begin{array}{c}\text { Minimum } \\
\text { value }\end{array}$ & $\begin{array}{c}\text { Maximum } \\
\text { value }\end{array}$ & $\begin{array}{c}\text { Average } \\
\text { output }\end{array}$ & $\begin{array}{c}\text { Standard } \\
\text { deviation }\end{array}$ & $\begin{array}{c}\text { Standard deviation } \\
\text { to average } \\
\text { output ratio } \\
(\%)\end{array}$ \\
\hline 3.1 & 475375 & 489297 & 483564 & 6027 & $1.2 \%$ \\
3.2 & 439688 & 451536 & 445935 & 4130 & $0.9 \%$ \\
3.3 & 646721 & 654642 & 649879 & 3382 & $0.5 \%$ \\
3.4 & 765027 & 791046 & 777331 & 11014 & $1.4 \%$ \\
3.5 & 771966 & 805266 & 795074 & 9755 & $1.2 \%$ \\
2.1 & 930074 & 950265 & 941506 & 7407 & $0.7 \%$ \\
2.2 & 918110 & 937830 & 923054 & 6648 & $0.7 \%$ \\
2.3 & 609310 & 631960 & 620766 & 6268 & $1 \%$ \\
2.4 & 322150 & 345040 & 334582 & 7213 & $2.1 \%$ \\
2.5 & 520040 & 511390 & 509762 & 5191 & $1 \%$ \\
\hline
\end{tabular}

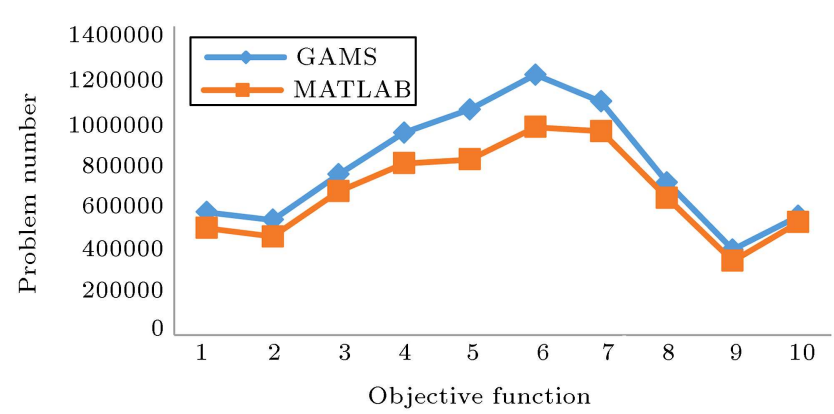

Figure 5. Curve of comparison of the objective function between the exact and metaheuristic solutions.

$T$ increased the processing time by about $2100 \%$ (21 order of magnitudes). Hence, this obvious difference ( $2 \%$ versus $2100 \%$ ) is well justifiable and affordable; indeed, it confirms the significant effect of the proposed metaheuristic algorithm.

A comparison between the results of the proposed algorithm and GAMS revealed that the algorithm found better solutions within a reasonable time, while GAMS failed to find the optimum solution in some cases. Further, GAMS required longer processing times than GA. Figures 5 and 6 show that GA outperforms GAMS.

Considering all comparisons and according to Figures 5 and 6 , it can be suggested that the advantages offered by the proposed GA for the mathematical model formulated in this research dominate outnumber its disadvantages, proving the effectiveness and capability of the algorithm to solve not only two-period and three-period problems, but also problems of higher programming periods. It is worth mentioning that, based on the criteria set by the decision-makers and the nature of the logistic network, different measurement units can be used to measure a period.

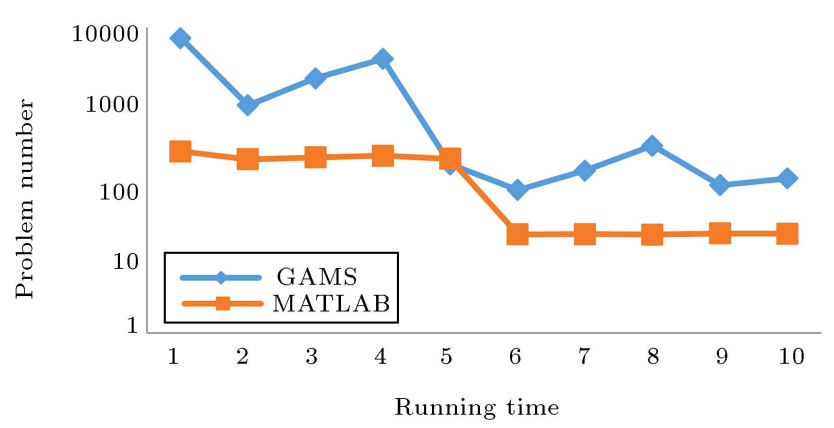

Figure 6. Logarithmic curve of comparison of the processing time between the exact and metaheuristic solutions.

In Figures 5 and 6, the comparative results and processing times of the exact and GA algorithm outputs are shown. The results confirm the superior performance of the proposed algorithm, such that the presented GA provides an efficient approach to the solution of the introduced problem.

By analyzing the algorithm robustness, the results of different runs of the algorithm are presented in Table 7 .

The results show that, in the worst case (i.e., problem number 2.4), the standard deviation to average output ratio was $2.1 \%$, while the average ratio for all cases was as low as $1.1 \%$, indicating the robustness of the proposed algorithm.

\section{Conclusion and recommendations}

Today, organizations need to design integrated distribution-collection networks because of various reasons imposed by governments, society, and competitors. Multi-period programming, multi-echelon structure, and other design variables must be appropriately 
taken into consideration before an applicable and closeto-reality model can be achieved. Furthermore, multiperiod programming enhances the level of flexibility. Every transpiration network needs to use different transportation modes, and the resent research considers the choice of transportation mode in various programming periods. Designing such a network entails more efforts from the researchers.

Considering these needs, this research started by proposing a mathematical model under several reasonable assumptions taken from the real world. The applicability of the proposed problem and the validity of the mathematical model were analyzed by solving the problem in GAMS software. Solution structure and complexity of the mathematical model were further studied, concluding that the mathematical model, especially medium- and large-sized cases, was practically impossible to solve via exact approaches as it took an extremely long time to be solved. Accordingly, there is a need for a solving algorithm with the capability of returning correct, rational, wellfitted, reliable solutions on an accepted time scale. By studying different solution approaches and the structure of the mathematical models and by means of available resources and references, metaheuristic genetic algorithm was found to be a proper approach to solving the research problem. GA was designed and coded in MATLAB software. Finally, based on the comparison of the results obtained via the exact approach and the metaheuristic algorithm outputs, the metaheuristic algorithm was found to be an effective and efficient approach to solving the problem.

In order to enhance supply chain efficiency, a logistics manager should consider various parameters when forming a logistics network. In order to meet particular regulations, reuse products, or decrease wastes, some supply chains need reverse logistics; this paper provides the logistics managers with a proper tool for such supply chains. The results validated the model and the performance of the proposed algorithm.

Based on the investigations and studies performed so far and considering the demands arisen in the real world, the following recommendations can be proposed for extending the mathematical model and getting it as close to the real world as possible:

1. Considering the idea of multi-objectivity within the model, i.e., interactions among such objectives as maximization of system responsiveness, minimization of negative environmental effects and delivery time, etc., can provide subjects for future research works;

2. Investigation of the uncertainties associated with such parameters as customer demands within different periods, transportation costs, and volume of returned products may be performed in future studies;

3. Performance of other metaheuristic algorithms such as TS and SA in this context can be compared to that of GA in order to further validate it.

\section{References}

1. Amin, S.H. and Zhang, G. "A multi-objective facility location model for closed-loop supply chain network under uncertain demand and return", Appl. Math. Model., 37(6), pp. 4165-4176 (2013).

2. Lambert, S., Riopel, D., and Abdul-Kader, W. "A reverse logistics decisions conceptual framework", Comput. Ind. Eng., 61(3), pp. 561-581 (2011).

3. Lee, D.H. and Dong, M. "A heuristic approach to logistics network design for end-of-lease computer products recovery", Transp. Res. Part E Logist. Transp. Rev., 44(3), pp. 455-474 (2008).

4. Lin, J.R., Nozick, L.K., and Turnquist, M.A. "Strategic design of distribution systems with economies of scale in transportation", Ann. Oper. Res., 144(1), pp. 161-180 (2006).

5. Du, F. and Evans, G.W. "A bi-objective reverse logistics network analysis for post-sale service", Comput. Oper. Res., 35(8), pp. 2617-2634 (2008).

6. Mehdizadeh, E., Afrabandpei, F., and Mohaselafshar, S. "Design of a multi-stage transportation network in a supply chain system: Formulation and efficient solution procedure", Scientia Iranica., 20(6), pp. 21882200 (2013).

7. Mirmajlesi, S.R. and Shafaei, R. "An integrated approach to solve a robust forward/reverse supply chain for short lifetime products", Computers \& Industrial Engineering., 97, pp. 222-239 (2016).

8. Taleizadeh, A.A. and Sadeghi, R. "Pricing strategies in the competitive reverse supply chains with traditional and e-channels: A game theoretic approach", International Journal of Production Economics, 215, pp. 48-60 (2019).

9. Fathollahi Fard, A.M. and Hajaghaei-Keshteli, M. "A tri-level location-allocation model for forward/reverse supply chain", Applied Soft Computing., 62, pp. 328346 (2018).

10. Badri, H., Bashiri, M., and Hejazi, T.H. "Integrated strategic and tactical planning in a supply chain network design with a heuristic solution method", Comput. Oper. Res., 40(4), pp. 1143-1154 (2013).

11. Nobari, A. and Kheirkhah, A. "Integrated and dynamic design of sustainable closed-loop supply chain network considering pricing", Scientia Iranica, 25(1), pp. $410-430$ (2018).

12. Cardoso, S.R., Barbosa-Póvoa, A.P.F.D.D., and Relvas, S. "Design and planning of supply chains with integration of reverse logistics activities under demand uncertainty", Eur. J. Oper. Res., 226(3), pp. 436-451 (2013). 
13. Pedram, A., Yusoff, N.B., and Udoncy, O.E. "Integrated forward and reverse supply chain: A tire case study", Waste Management., 60, pp. 460-470 (2017).

14. Lieckens, K. and Vandaele, N. "Reverse logistics network design with stochastic lead times", Comput. Oper. Res., 34(2), pp. 395-416 (2007).

15. Aghezzaf, E. "Capacity planning and warehouse location in supply chains with uncertain demands", $J$. Oper. Res. Soc., 56(4), pp. 453-462 (2005).

16. Shaharudin, M.R., Govindan, K., and Zailani, S. "Product return management: Linking product returns, closed-loop supply chain activities and the effectiveness of the reverse supply chains", Journal of Cleaner Production., 149(15), pp. 1144-1156 (2017).

17. Lowe, T.J., Wendell, R.E., and Hu, G. "Screening location strategies to reduce exchange rate risk", Eur. J. Oper. Res., 136(3), pp. 573-590 (2002).

18. Martel, A., Beauregard, R., and Vila, D. "Designing logistics networks in divergent process industries: A methodology and its application to the lumber industry", Int. J. Prod. Econ., 102(2), pp. 358-378 (2006).

19. Karabakal, N., Günal, A., and Ritchie, W. "Supplychain analysis at Volkswagen of America", Interfaces., 30(4), pp. 46-55 (2000).

20. Ambrosino, D. and Scutellà, M.G. "Distribution network design: new problems and related models", Eur. J. Oper. Res., 165(3), pp. 610-624 (2005).

21. Avittathur, B., Shah, J., and Gupta, O.K. "Distribution centre location modelling for differential sales tax structure", Eur. J. Oper. Res., 162(1), pp. 191-205 (2005).

22. Daskin, M.S., Coullard, C.R., and Shen, Z.J.M. "An inventory-location model: Formulation, solution algorithm and computational results", Ann. Oper. Res., 110(1-4), pp. 83-106 (2002).

23. Jang, Y.J., Jang, S.Y., and Chang, B.M. "A combined model of network design and production/distribution planning for a supply network", Comput. Ind. Eng., 43(1), pp. 263-281 (2002).

24. Melo, M.T., Nickel, S., and Saldanha da Gama, F. "Dynamic multi-commodity capacitated facility location: a mathematical modeling framework for strategic supply chain planning", Comput. Oper. Res., 33(1), pp. 181-208 (2006).

25. Syam, S.S. "A model and methodologies for the location problem with logistical components", Comput. Oper. Res., 29(9), pp. 1173-1193 (2002).

26. Van Weele, A.J. "Purchasing \& supply chain management: analysis, strategy, planning and practice", Cengage Learning EMEA (2009).

27. Cordeau, J.F., Pasin, F., and Solomon, M.M. "An integrated model for logistics network design", Ann. Oper. Res., 144(1), pp. 59-82 (2006).

28. Yan, H., Yu, Z., and Cheng, T.C.E. "A strategic model for supply chain design with logical constraints: formulation and solution", Comput. Oper. Res., 30(14), pp. 2135-2155 (2003).
29. Zhou, W.Q. and Chen, L. "Research on the inventory control of the remanufacturing reverse logistics based on the quantitative examination", Scientia Iranica, 24(2), pp. 741-750 (2017).

30. Wilhelm, W., Liang, D., and Rao, B. "Design of international assembly systems and their supply chains under NAFTA", Transp. Res. Part E Logist., 41(6), pp. 467-493 (2005).

31. Olivares-Benitez, E., Ríos-Mercado, R.Z., and González-Velarde, J.L. "A supply chain design problem with facility location and bi-objective transportation choices", Artic. Metrics, 20(3), pp. 729-753 (2010).

32. Heydari, J., Govindan, K., and Jafari, A. "Design of a multi-stage transportation network in a supply chain system: Formulation and efficient solution procedure", Reverse and closed loop supply chain coordination by considering government role., 52, pp. 379-398 (2017).

33. Giri, B.C., Chakraborty, A., and Maiti, T. "Pricing and return product collection decisions in a closed-loop supply chain with dual-channel in both forward and reverse logistics", Journal of Manufacturing Systems., 42, pp. 104-123 (2017).

34. Khakim Habibi, M.K., Olga, B., and Van-Dat, C. "Collection-disassembly problem in reverse supply chain", International Journal of Production Economics., 183, pp. 334-344 (2017).

35. Butzer, S., Schötz, S., and Petroschke, M. "Development of a performance measurement system for international reverse supply chains", procedia CIRP., 61, pp. 251-256 (2017).

36. Goh, M., Lim, J.Y.S., and Meng, F. "A stochastic model for risk management in global supply chain networks", Eur. J. Oper. Res., 182(1), pp. 164-173 (2007).

37. Lu, Z. and Bostel, N. "A facility location model for logistics systems including reverse flows: The case of remanufacturing activities", Comput. Oper. Res., 34(2), pp. 299-323 (2007).

38. Üster, H., Easwaran, G., and Akçali, E. "Benders decomposition with alternative multiple cuts for a multi-product closed-loop supply chain network design model", Navel Res. Logistic., 54(6), pp. 890-907 (2007).

39. Min, H. and Ko, H.J. "The dynamic design of a reverse logistics network from the perspective of thirdparty logistics service providers", Int. J. Prod. Econ., 113(1), pp. 176-192 (2008).

40. Lee, C.K.M. and Chan, T.M. "Development of RFIDbased reverse logistics system", Expert Syst. Appl., 36(5), pp. 9299-9307 (2009).

41. Trappey, A.J.C., Trappey, C.V., and Wu, C.R. "Genetic algorithm dynamic performance evaluation for RFID reverse logistic management", Expert Syst. Appl., 37(11), pp. 7329-7335 (2010).

42. Fakhrzad, M.B. and Moobed, M. "A GA model development for decision making under reverse logistics", Int. J. Ind. Eng., 21(4), pp. 211-220 (2010). 
43. Zegordi, S.H., Abadi, I.N.K., and Nia, M.A.B. "A novel genetic algorithm for solving production and transportation scheduling in a two-stage supply chain", Comput. Ind. Eng., 58(3), pp. 373-381 (2010).

44. Modiri-Delshad, M., Kaboli, S.H.A., and TaslimiRenani, E. "Backtracking search algorithm for solving economic dispatch problems with valve-point effects and multiple fuel options", Energy., 116, pp. 637-649 (2016).

45. Kaboli, S.H.A., Selvaraj, J., and Rahim, N.A. "Longterm electric energy consumption forecasting via artificial cooperative search algorithm", Energy., 115, pp. 857-871 (2016).

46. Rafieerad, A.R., Bushroa, A.R., and Nasiri-Tabrizi, B. "Toward improved mechanical, tribological, corrosion and in-vitro bioactivity properties of mixed oxide nanotubes on Ti-6Al-7Nb implant using multiobjective PSO", Journal of the Mechanical Behavior of Biomedical Materials, 69, pp. 1-18 (2017).

47. Kaboli, S.H.A., Fallahpour, A., and Selvaraj, J. "Longterm electrical energy consumption formulating and forecasting via optimized gene expression programming", Energy., 126, pp. 144-164 (2017).

48. Kaboli, S.H.A., Selvaraj, J., and Rahim, N.A. "Rainfall optimization algorithm: a population based algorithm for solving constrained optimization problems", Journal of Computational Science., 19, pp. 31-42 (2017).

49. Sebtahmadi, S.S., Borhan Azad, H., and Kaboli, S.H.A. "A PSO-DQ current control scheme for performance enhancement of Z-source matrix converter to drive IM fed by abnormal voltage", in IEEE Transactions on Power Electronics, 99, pp. 1666-1681 (2018).

50. Mansouri, M., Kaboli, S.H.A., and Ahmadian, J. "A hybrid Neuro-Fuzzy-PI speed controller for BLDC enriched with an integral steady state error eliminator", Control System, Computing and Engineering
(ICCSCE), IEEE International Conference on, IEEE (2012).

51. Modiri-Delshad, M., Koohi-Kamali, S., and Taslimi, E. "Economic dispatch in a microgrid through an iterated-based algorithm", Clean Energy and Technology (CEAT), IEEE Conference on, IEEE (2013).

52. Krarup, J. and Pruzan, P.M. "The simple plant location problem: survey and synthesis", Eur. J. Oper. Res., 12(1), pp. 36-81 (1983).

\section{Biographies}

Alireza Eydi is an Associate Professor of Industrial Engineering in the Faculty of Engineering at University of Kurdistan, Iran. He received his PhD from the Department of Industrial Engineering at Tarbiat Modares University, Tehran, Iran in 2009. His main areas of teaching and research interests include supply chain and transportation planning and network optimization problems include routing and location problems on networks.

Saeed Fazayeli is a PhD student of Industrial Engineering in the Faculty of Engineering at University of Kurdistan, Sanandaj, Iran. He received his MSc degree from Iran University of Science and Technology, Tehran, Iran. His main areas of research interests are Location-Routing problems and multimodal transportation planning.

Hossein Ghafouri is an MSc graduate of Industrial Engineering in the faculty of Engineering at University of Kurdistan, Sanandaj, Iran. He received his BSc from the Department of Engineering at University of Payam Nour Tabriz, Tabriz, Iran in 2015. His thesis subject revolves around supply chain configuration problem. 